\title{
Submersible study of lower continental slope-abyssal plain contact*
}

\author{
Xavier Le Pichon, $\nmid$ Roger Hékinian, $†$ Jean Francheteau $\nmid$ and Daniel Carré $\dagger$
}

(Received 1 July 1974; in revised form 14 March 1975; accepted 14 March 1975)

\begin{abstract}
Two dives of the bathyscaphe Archimede on the 'lower continental slope-abyssal plain' contact northwest of Corsica have revealed a sharp contact between the upper sedimentary cover of the two domains. The lower slope seems highly unstable and it is suggested that large-scale sliding of the upper sedimentary layer is characteristic. In contrast, the abyssal plain has a very tranquil sedimentation. The results of a major mud flow triggered by the bathyscaphe are discussed.
\end{abstract}

\section{INTRODUCTION}

IN OCTOBER 1972, the bathyscaphe Archimède made a series of training dives-to a $2600-\mathrm{m}$ water-depth off northwest Corsica in order to test new equipment. Two of these dives (72-5 and 72-7) were made at the limit of the lower continental slope and the abyssal plain near an acoustic transponder ( $\mathrm{X}^{\prime} 4$ in Fig. 1) with respect to which the submersible could position itself with an accuracy of 10 to $200 \mathrm{~m}$ within a radius of $1450 \mathrm{~m}$. The position of $\mathrm{X}^{\prime} 4$ with respect to the geographic grid is not known to better than 200 to $300 \mathrm{~m}$. We feel, however, that the position of the transponder shown on Fig. 1 leads to a good agreement with the relief revealed by the bathymetric map. These dives, in spite of technical shortcomings, gave some unexpected information about the upper sedimentary structure of the area.

\section{DIVE $72-5$}

Archimede landed on the sea floor at a depth of about $2450 \mathrm{~m}$, on the lower continental slope, $850 \mathrm{~m}$ east of transponder $\mathrm{X}^{\prime} 4$. It then proceeded westward downslope at full speed (approximately $40 \mathrm{~m} \mathrm{~min}^{-1}$ ) in visual contact with the bottom. Figure 1 shows that $\mathrm{X}^{\prime} 4$ is located just above the edge of the abyssal plain, north of some channel or gully. The local slope is 5 to $6^{\circ}$ but steepens eastward to more than $10^{\circ}$ in the zone of landing of dive 72-5. While moving downslope, about 5 to $6 \mathrm{~m}$ off the bottom, the observers (JF and
$\mathrm{RH}$ ) could see an alternation of two types of terrain. Over the first $300 \mathrm{~m}$, the topography was locally gently undulating with evidence of numerous borrowers (Fig. 2a). A series of sedimentary ridges with a wavelength of a few meters and an amplitude of 1 to $2 \mathrm{~m}$ characterized the next $200 \mathrm{~m}$. These ridges were oriented north-northwest-south-southeast roughly parallel to the isobaths. As can be seen on Fig. 2b, there was no evidence of current activity, although abundant traces of burrowers were obvious. The ridges were absent over the next $80 \mathrm{~m}$ (from $12 \mathrm{~h} 52$ to $12 \mathrm{~h} 55$ on Fig. 1) to appear progressively again at $12 \mathrm{~h} 55$ their amplitude increasing downslope.

Because of this unexpected increase in amplitude of the ridges downslope, at 1259, Archimède could not avoid the crest of one of these ridges, bounced off (Fig. 2d) and finally stopped $10 \mathrm{~m}$ further away with its keel buried in about $1 \mathrm{~m}$ of mud (Fig. 1). Figure 2c shows a close-up of the bottom sediment just before the first hit. Note again the absence of visible traces of current action and the sporadic burrowing. A chunk of sediment was scraped from the submersible on its return to the surface. It consists of a yellowish grey sandy foraminiferal ooze made

*Contribution No. 288 of the Département Scientifique, Centre Océanologique de Bretagne.

tCentre Océanologique de Bretagne, B. P. 337, 29273 Brest, France. 


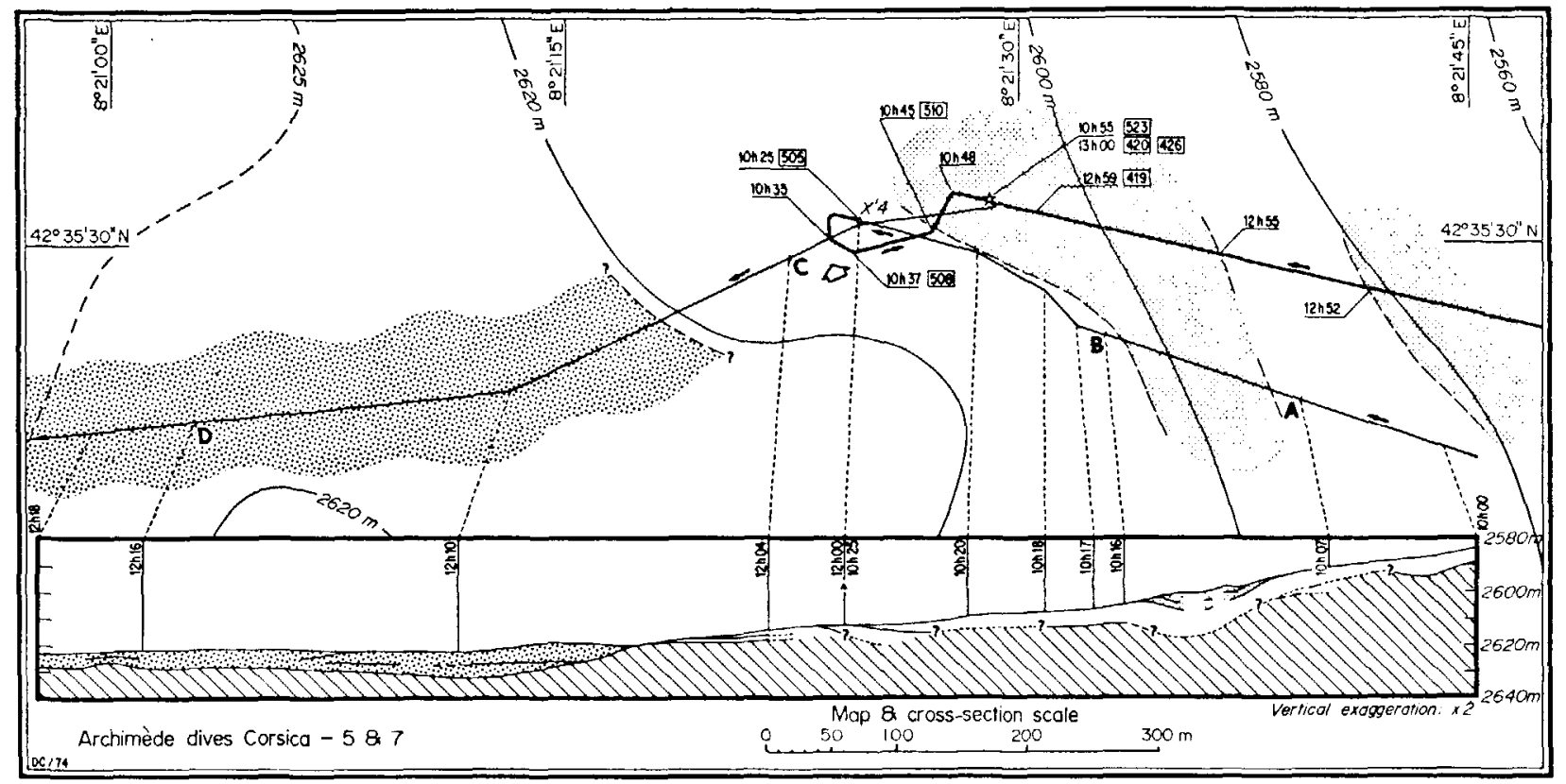

Fig. 1. Upper part. Bathymetric map of main area of dives 72-5 and 72-7 west of Corsica. Contours in corrected meters taken from the bathymetric chart of the Muse Océanographique de Monaco (PIERrot, 1969). Heavy lines $(\rightarrow)$ correspond to the track line of dive 72-7 when in visual contact with the bottom. The lighter continuous lines (-) indicates the track line of dive 72-7 when out of visual contact with the bottom. Two parallel lines (=) represent the dive 72-5 track line in visual contact with bottom. The star indicates the end of dive 72-5. 419 indicates location of some of the bottom photographs shown in Figs. 2 and 4. The broad arrow indicates the main direction of current as inferred from photographs 506 to 508. Pale dotted areas correspond to zones of elongated sedimentary ridges. Dark dotted area corresponds to abyssal plain region. $X^{\prime} 4$ is the location of the acoustic transponder.

Lower part. Bathymetric cross-section obtained during dive $72-7$, showing subsurface major reflectors obtained with a $10-\mathrm{kHz}$ echo-sounder.

up of $60 \%$ of tests of foraminifera, $25 \%$ of sand and $15 \%$ of an association of silt and clay. The sand fraction contains subangular quartz, albite, orthoclase, with minor microcline and heavy opaque minerals. The sand fraction corresponds to the erosion of a silicic igneous complex, probably granite or granodioritic. This sandy material could have been derived from granitic formations widely spread in Corsica (BonNal, Parsy, Priou-Lacazedieu and Durand-Delga, 1973; Amaudric du Chaffaut and Lemoine, 1974).

While the bathyscape was immobilized on the bottom, the divers saw dense clouds of sediment in suspension flowing rapidly downslope. The density and height above bottom of the clouds were such that vision was obscured most of the time both through the port-holes and on the television monitor. Intermittently, the height of the flow of muddy water was smaller and revealed a gentle and smooth burrow-mottled bottom
(Fig. 2e). A rough estimate of the speed of flow can be based on the time necessary for a cloud of mud to drift over the bottom through the whole field of vision. We tentatively conclude that the speed was greater than 1 to $2 \mathrm{~m}$ per second. Forty-five minutes after the hit, Archimède suddenly freed itself and started to go up irreversibly after releasing its security ballast.

\section{DIVE $72-7$}

Although the objectives of dive 72-7 were mainly technological, part of the dive was aimed at investigating the effect of the impact of Archimède on the bottom during dive 72-5. The observations made were of two different types. The first, made 30 to $50 \mathrm{~m}$ off the bottom, were planned to provide a continuous bottom and sub-bottom profile along the downslope track followed by dive $72-5$ and to continue it beyond transponder $\mathrm{X}^{\prime} 4$ into the abyssal plain. Observa- 


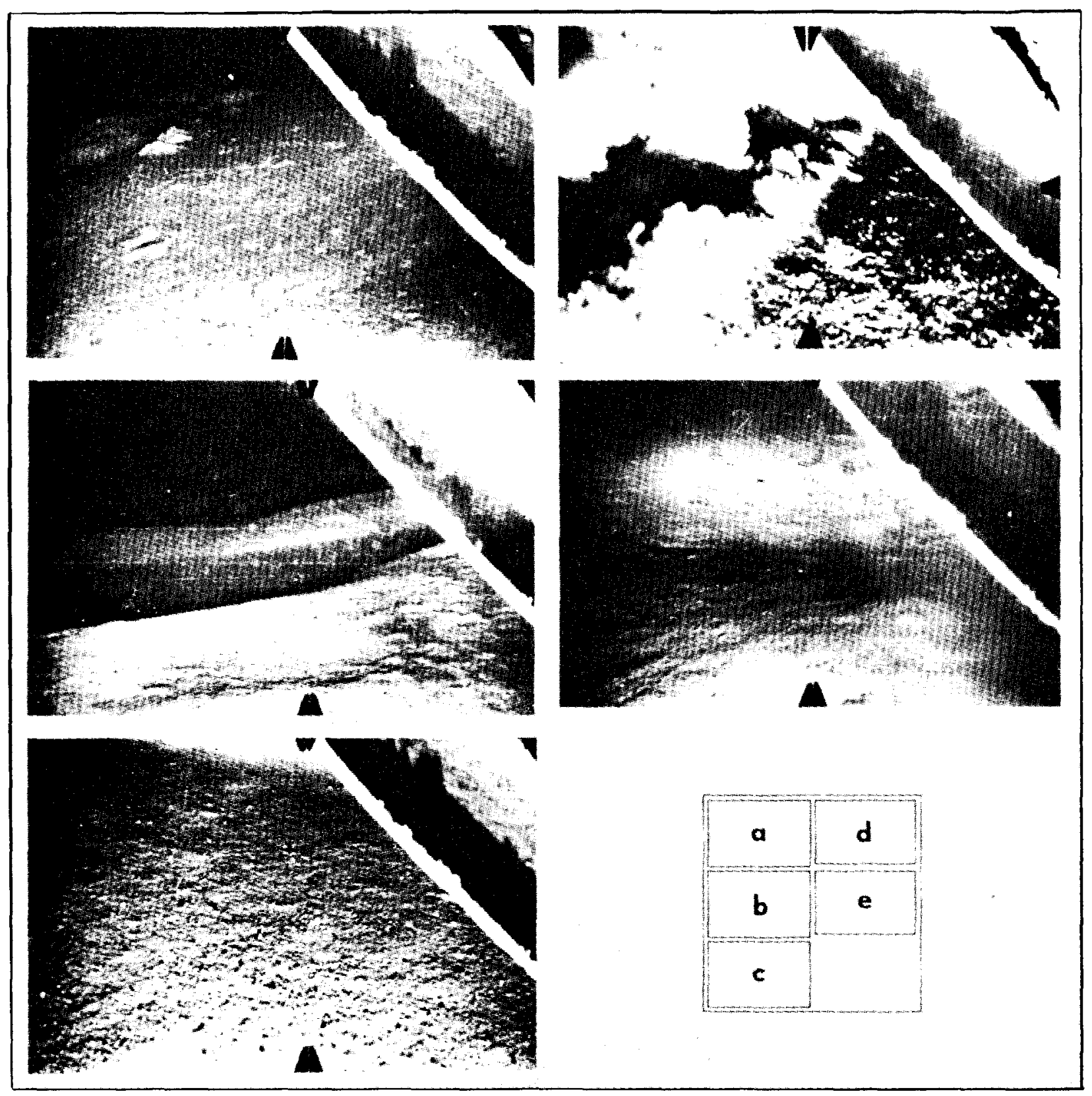

Fig. 2. Bottom photographs taken during dive 72-5 west of Corsica.

(a) Photo 365 at $12 \mathrm{~h} 40$. Gently undulating topography. Burrow mottled sediment with isolated large lumps of sediment possibly due to animal action. Object on upper right corner of this and other photographs is part of Archimede frame.

(b) Photo 383 at $12 \mathrm{~h} 48$. Elongated sedimentary ridges oriented north-northwest-south-southeast parallel to isobaths with a wavelength of a few meters. Abundant burrowing effects and no visible current action.

(c) Photo 419 at $12 \mathrm{~h} 59$. Close-up of bottom sediment just before first hit on slope of large sediment ridge. No visible traces of current activity. Sporadic burrowing. Photographs $2 \mathrm{c}$ and $2 \mathrm{~d}$ represent the only 'close up', taken while Archimede was in contact with or very close to the bottom. This results in excellent definition and resolution of the coarse texture of the sediment.

(d) Photo 420 at 12 h 59 . First hit. Clouds of mud.

(e) Photo 426 at $13 \mathrm{~h} 26$. Bathyscaphe is partly buried in mud since $13 \mathrm{~h} 00$. Clouds of suspended particles are drifting at a few meters per second just above bottom. 


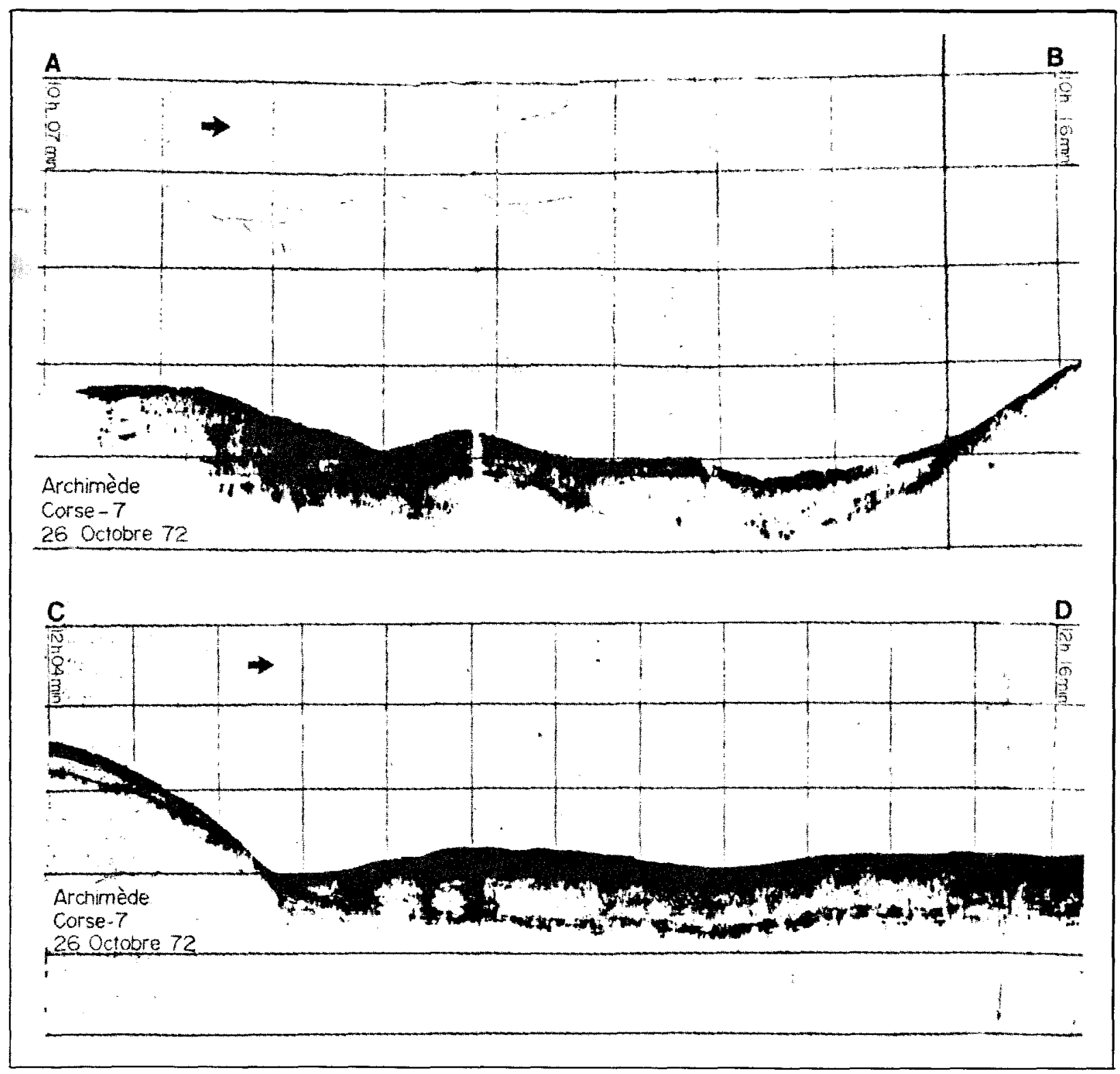

Fig. 3. Upper: Photograph of $10-\mathrm{kHz}$ echo-sounder record obtained above sedimentary ridge area of lower continental slope (section AB). From $10 \mathrm{~h} 13$ to $10 \mathrm{~h} 16$, the bathyscaphe was sinking progressively nearer to the sea-floor which results in an apparent upward slope of the bottom. Vertical exaggeration: about $>2$. Vertical scale: $10 \mathrm{~m}$ per square.

Lower: $10-\mathrm{kHz}$ echo-sounder record of contact between lower continental slope and abyssal plain. Note sharpness of contact. Vertical exaggeration: about $\times 3$. The record interpreted in Fig. 1 (lower part) has been corrected for the varying depth of the bathyscaphe. 

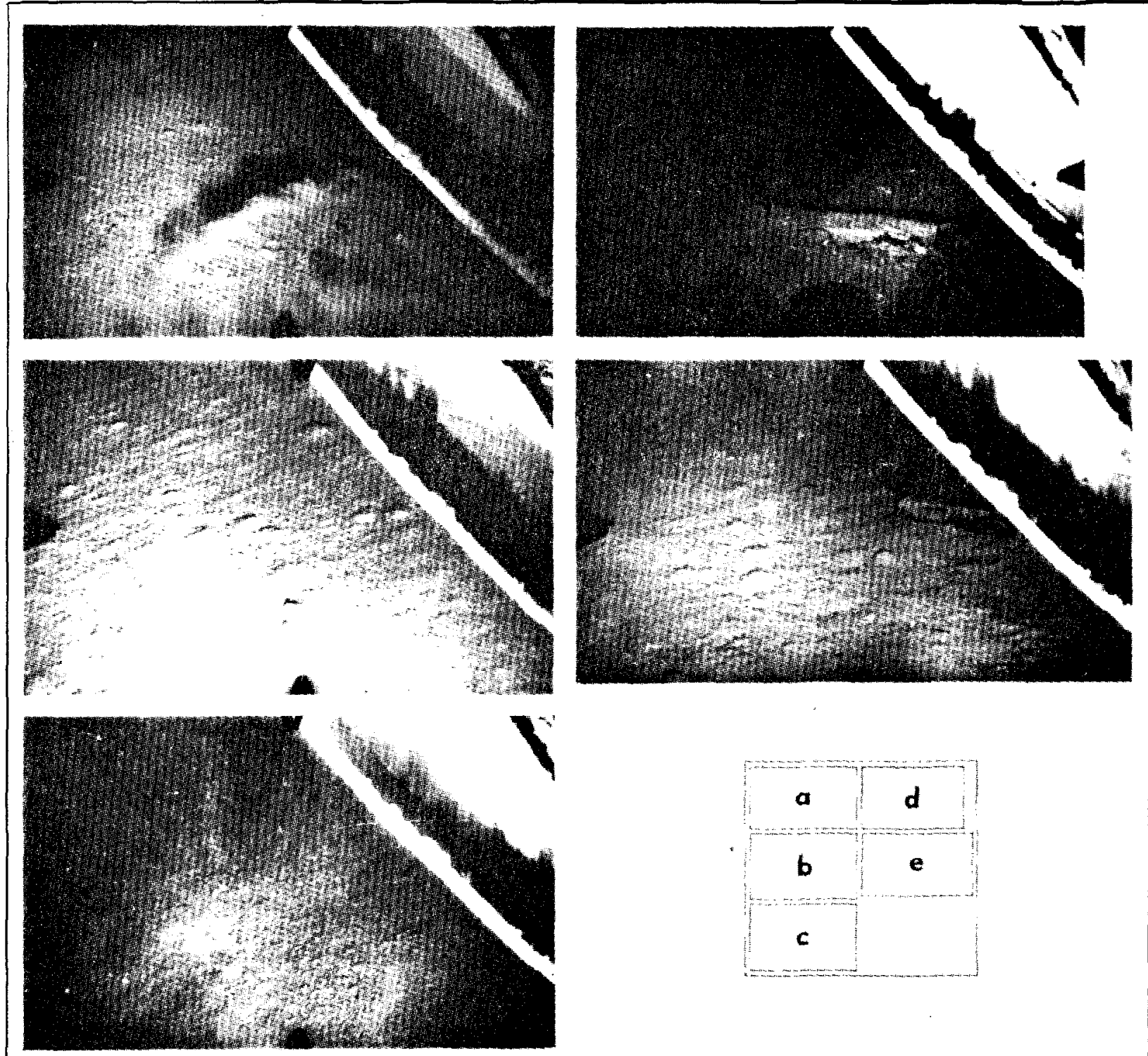

Fig. 4. Bottom photographs taken during dive 72-7 west of Corsica.

(a) Photo 505 at $10 \mathrm{~h} 25$. Relatively flat homogeneous bottom with small size burrowing irregularly distributed. No trace of current activity can be observed in the sediment structure. Note the coarse texture of sediment as in photo 419 (Fig. 2c). Cloud of mud slowly drifting away is due to bathyscaphe landing.

(b) Photo 508 at $10 \mathrm{~h} 37$. Relatively flat bottom. Current marks indicate a current flowing toward the north-northwest roughly parallel to the bottom contours. Scattered cones due to burrowers. Coarse texture sediment.

(c) Photo 510 at $10 \mathrm{~h} 45$. Bottom sloping rather steeply toward the lower left corner (west-southwest). Coarse detritus of sediment lumps has partly covered up the other type of sediment. Notice the almost total disappearance of burrow mottling. This photograph is taken about $4 \mathrm{~m}$ off the bottom, much farther away than photograph 419 (Fig. 2c).

(d) Photo 523 at $10 \mathrm{~h} \mathrm{55.} \mathrm{Site} \mathrm{where} \mathrm{bathyscaphe} \mathrm{was} \mathrm{partly} \mathrm{buried} \mathrm{during} \mathrm{dive} \mathrm{72-5.} \mathrm{The} \mathrm{dark} \mathrm{oval} \mathrm{patches} \mathrm{are}$ the ballast piles left by the bathyscaphe in order to free itself. Notice the semiconsolidated sediments which have been upturned by the bathyscaphe.

(e) Photo 590 at $13 \mathrm{~h} 40$. Site $2 \mathrm{~km}$ further west on the abyssal plain. Tranquil muddy bottom with very numerous small craters of burrowing animals. Note contrast with all other photographs upslope. 
tions made 3-5 $\mathrm{m}$ off the bottom near $\mathrm{X}^{\prime} 4$ were planned to inspect visually the zone of impact.

The lower part of Fig. 1 is a composite bottom and sub-bottom profile which summarizes the first type of observations. The $10-\mathrm{kHz}$ sounder gave an average sub-bottom penetration of $10 \mathrm{~m}$ in this area. Figure 3 shows two samples of the record obtained: one ( $10 \mathrm{~h} 07$ to $10 \mathrm{~h} \mathrm{16)}$ (section $A B)$ is located over the area of sedimentary ridges; the other one $(12 \mathrm{~h} 04$ to $12 \mathrm{~h} \mathrm{16})$ is located over the zone of very sharp contact between the lower continental slope and the abyssal plain. Although the portion of record between 9 h 58 and 10 h 25 (just before landing) is located $100 \mathrm{~m}$ further south than the track followed during dive $72-5$, it is reasonable to assume that portion $\mathrm{AB}$ (Fig. 1, Fig. 3 top) correlates with the zone of sedimentary ridges which was entered by the bathyscaphe at 12 h 55 during dive 72-5. We suggest that the whole zone is due to downslope siiding of the upper $10 \mathrm{~m}$-thick sedimentary layer over a width of $100 \mathrm{~m}$ or so and over an unknown length, perhaps several hundred meters, parallel to the isobaths. This sliding resulted in crumpling of the $10 \mathrm{~m}$-thick layer, thus producing the sedimentary ridges parallel to the isobaths with an increasing amplitude downslope. The fact that the lowermost layer is not affected by the 'crumpling' and outcrops at both ends argues against a contour current origin or a direct sait diapirism origin.

The observations made during dive $72-7$ while in visual contact with the bottom between $10 \mathrm{~h} 25$ and $10 \mathrm{~h} 55$ tend to confirm this interpretation. Near $X^{\prime} 4$ (Fig. 4a), there is an undisturbed relatively flat homogeneous bottom. Between $10 \mathrm{~h} 35$ and $10 \mathrm{~h} \mathrm{37}$, further downslope, the bottom is still undisturbed but there is clear evidence of north-northwest-flowing bottom contour current (Fig. 4b), that is current flowing at the base of the continental slope and parallel to it.

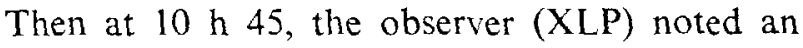
abrupt change in the nature of the bottom (Fig. 4c). The bottom was coming up rather sharply toward the east-northeast. Coarse lumps of sediment had partly covered up the other type of sediment and little burrow mottling could be seen. Archimède was entering the lowermost part of the supposed zone of sliding, about $30 \mathrm{~m}$ south-southwest of the site where the submersible had been partly buried (Fig. 4d). We suggest that the very coarse sediment was deposited by the mud clouds triggered by the Archimede hit. We do not know whether the upturned layer of semiconsolidated sediment seen on Fig. $4 d$ was due to compaction by the submersible or whether there is such a compact layer close to the surface in this area. In any case, the large amplitude of the sedimentary ridges seen between $10 \mathrm{~h} 45$ and $10 \mathrm{~h} 55$ and their abrupt ending south of the point corresponding to $10 \mathrm{~h} 45$ support our interpretation. The whole zone of gliding of the upper sedimentary layer would be such that crumpiing progressively increases downslope. It is tempting to suggest that the other zone of sedimentary ridges above the $2580-\mathrm{m}$ isobath corresponds to a similar zone of superficial sliding.

The sub-bottom sounder record obtained while leaving $X^{\prime} 4$ (Fig. 1 and Fig. 3-bottom) shows that the 'base of continental slope-abyssai plain' contact is abrupt and may actually oe a zone of erosion. Note in particular the outcropping of the sedimentary layers at the surface. This zone of erosion may be the result of both slumping and contour current action at the base of the slope. In any case, the landing made on the abyssal plain $2 \mathrm{~km}$ further west (Fig. $4 \mathrm{e}$ ) revealed a completely different type of bottom, obviously resulting from very tranquil muddy sedimentation with intense activity of numerous burrowers.

\section{DISCUSSION}

The evidence obtained suggests that the lower continental slope is a zone where at least the uppermost layer of sediments is highly unstable, so that large portions may slide down a few meters to a few tens of meters, resulting in crumpling which produces sedimentary ridges progressively increasing in amplitude and wavelength toward the lower part of the slide. The width of such a slide seems to be about $100 \mathrm{~m}$ and it seems to affect a layer about $10 \mathrm{~m}$ thick. These slides may trigger turbidity currents or, at least, feed the contour currents at the base of the 
slope with mud in suspension. Although it is unlikely that salt diapirism is the direct cause of the sedimentary ridges, we cannot rule out that the readjustment of the uppermost sedimentary layer and the abrupt contact at the base of the continental slope are related in some way to migration of the deep Messinian evaporitic layer (Drooger, 1973).

It is difficult to explain why the impact of the bathyscaphe resulted in muddy water downslope flow for more than $45 \mathrm{~min}$ after the impact. It may be that the very small motion of Archimede trying to free itself from the mud was continuous enough to trigger small muddy water flows. There is little doubt in any case that no coarse sediments were deposited beyond $70 \mathrm{~m}$ downslope fi om the site of impact. We realize that the information is still very preliminary but we consider that it indicates that the processes of dynamic sedimentation in this area are very complex, change over very short distances and need to be studied in three dimensions with a high precision of localization. The submersible is, to our knowledge, the only possible tool to achieve such a study. We note that, although it has not been reported in the literature, two other such incidents involving Archimède surveys over the southern France lower continental slope have resulted in similar downslope mud flows during tens of minutes (G. Pautot and $\mathrm{G}$. Bellaiche, personal communication, 1974).

Acknowledgements-The authors are indebted to ali members of the scientific parties, the Captain and the crew of the support ship Marcel Le Bihan (Marine Nationale) who participated in the 1972 cruise near Corsica. We are grateful to CC. DE Froberville, L. V. Harismendy and other members of the Archimede group and personnel from CNEXO-Section des Engins whose effort made possible the success of the diving program. We acknowledge the helpful criticisms of one of the reviewers.

\section{REFERENCES}

Amaudric du Chaffaut S. and M. Lemolne (1974) Découverte d'une série Jurassico-Crétacé d'affinités Briançonnaises transgressive sur la marge interne de la Corse granitique. Compte rendu hebdomadaire des séances de l'Académie des sciences, série D, 1317-1320.

Bonnal M., Parsy A., A. Priou-Lacazedieu and M. Durand-Delga (1973) Sur la structure de la Balagne sédimentaire (Corse). Compte rendu hebdomadaire des séances de l'Académie des sciences, série D, 1949-1952.

DroOger C. W., editor (1973) Messinian events in the Mediterranean, North Holland, 272 pp.

PIERrot S. (1969) Carte bathymétrique de la mer Ligure, in 16 sheets, scale $1 / 50000$, edited by Musée Océanographique de Monaco, Monaco. 